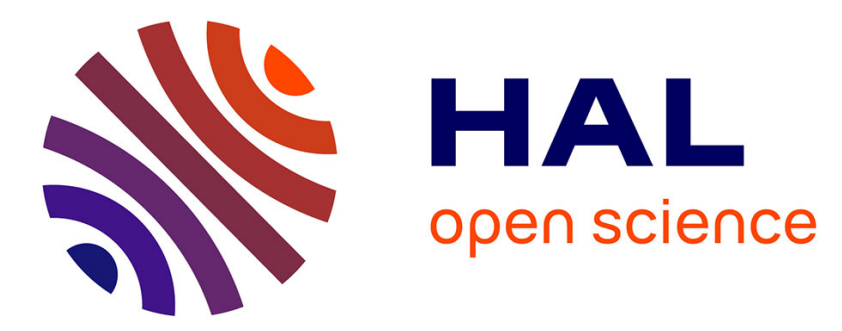

\title{
Complementary crops and landscape features sustain wild bee communities
}

Kyle T. Martins, Cécile H. Albert, Martin J. Lechowicz, Andrew Gonzalez

\section{To cite this version:}

Kyle T. Martins, Cécile H. Albert, Martin J. Lechowicz, Andrew Gonzalez. Complementary crops and landscape features sustain wild bee communities. Ecological Applications, 2018, 28 (4), pp.1093 - 1105. 10.1002/eap.1713. hal-01896060

\section{HAL Id: hal-01896060 https://hal-amu.archives-ouvertes.fr/hal-01896060}

Submitted on 15 Oct 2018

HAL is a multi-disciplinary open access archive for the deposit and dissemination of scientific research documents, whether they are published or not. The documents may come from teaching and research institutions in France or abroad, or from public or private research centers.
L'archive ouverte pluridisciplinaire HAL, est destinée au dépôt et à la diffusion de documents scientifiques de niveau recherche, publiés ou non, émanant des établissements d'enseignement et de recherche français ou étrangers, des laboratoires publics ou privés. 


\title{
Complementary crops and landscape features sustain wild bee communities
}

\author{
Kyle T. Martins, ${ }^{1,3}$ Cécile H. Albert, ${ }^{2}$ Martin J. Lechowicz, ${ }^{1}$ and Andrew Gonzalez ${ }^{1}$ \\ ${ }^{1}$ Department of Biology, McGill University, 1205 Docteur Penfield Avenue, Montréal, Québec H3A 1 B1 Canada \\ ${ }^{2}$ Aix Marseille Univ, Univ Avignon, CNRS, IRD, IMBE, Technopôle Arbois-Méditerranée Bât, Villemin - BP 80, \\ F-13545 Aix-en-Provence Cedex 04, France
}

\begin{abstract}
Wild bees, which are important for commercial pollination, depend on floral and nesting resources both at farms and in the surrounding landscape. Mass-flowering crops are only in bloom for a few weeks and unable to support bee populations that persist throughout the year. Farm fields and orchards that flower in succession potentially can extend the availability of floral resources for pollinators. However, it is unclear whether the same bee species or genera will forage from one crop to the next, which bees specialize on particular crops, and to what degree inter-crop visitation patterns will be mediated by landscape context. We therefore studied local- and landscape-level drivers of bee diversity and species turnover in apple orchards, blueberry fields, and raspberry fields that bloom sequentially in southern Quebec, Canada. Despite the presence of high bee species turnover, orchards and small fruit fields complemented each other phenologically by supporting two bee genera essential to their pollination: mining bees (Andrena spp.) and bumble bees (Bombus spp.). A number of bee species specialized on apple, blueberry, or raspberry blossoms, suggesting that all three crops could be used to promote regional bee diversity. Bee diversity (rarefied richness, wild bee abundance) was highest across crops in landscapes containing hedgerows, meadows, and suburban areas that provide ancillary nesting and floral resources throughout the spring and summer. Promoting phenological complementarity in floral resources at the farmstead and landscape scales is essential to sustaining diverse wild bee populations.
\end{abstract}

Key words: apple; bees; blueberry; community ecology; complementarity; ecosystem services; landscape ecology; raspberry; wild pollinators.

\section{INTRODUCTION}

There is growing evidence that wild bees provide essential pollination services that cannot easily be replaced by managed honey bees (Garibaldi et al. 2013, Mallinger and Gratton 2015). For some crops (e.g., apple, blueberry, raspberry), wild species may even be more efficient pollinators than honeybees (Kevan et al. 1990, Willmer et al. 1994, Javorek et al. 2002, Moisan-Deserres et al. 2014, Park et al. 2016). Diverse wild-bee communities can enhance the quantity, quality, and temporal stability of pollination (Klein et al. 2009, Garibaldi et al. 2011, Rader et al. 2013), as well as fruit production (Brittain et al. 2013, Garibaldi et al. 2013, 2014, Bartomeus et al. 2014). Wild bee richness predicts plant reproductive success better than bee abundance alone (Fontaine et al. 2005, Hoehn et al. 2008, Albrecht et al. 2012, Rogers et al. 2014, Blitzer et al. 2016). Given declines in wild bee populations (Goulson et al. 2008, Potts et al. 2010, Bartomeus et al. 2013, Carvalheiro et al. 2013), assessing the environmental determinants of their abundance and diversity at farms is critical to the sustainability of crop pollination (Kremen et al. 2007).

To the extent that they mediate floral and nesting resource availability, both local agricultural management and landscape context influence wild bee populations in agroecosystems (Ricketts et al. 2008, Lonsdorf et al. 2009, Kennedy

Manuscript received 2 December 2017; revised 27 January 2018; accepted 9 February 2018

3 E-mail: kyle.martins@mcgill.ca et al. 2013, Garibaldi et al. 2014, Mallinger et al. 2016). At the local scale, enhancing the density and diversity of flowers in hedgerows (Payette and De Oliveira 1989, Schulp et al. 2014), field margins (Rands and Whitney 2010), flower strips (Haaland et al. 2011, Wratten et al. 2012), and (semi-) natural land nearby farms (Martins et al. 2015) can increase wild bee abundance and diversity (Garibaldi et al. 2014, Venturini et al. 2016). At the landscape scale, wild bees track resources from forests to agricultural fields and meadows throughout the year (Mandelik et al. 2012).

Indeed, the replacement of natural areas by croplands less hospitable to pollinators (e.g., monocultures) means that there is less floral forage over shorter periods (Ollerton et al. 2014, Scheper et al. 2014). Habitat loss driven by land use change may be one of the major causes of bee declines in North America (Burkle et al. 2013). Bee densities can respond positively to mass-flowering crops in agricultural landscapes (Westphal et al. 2003, 2009, Todd et al. 2016), but these are often in bloom for just a few weeks and unable to support bee populations throughout the year.

Promoting the phenological complementarity of floral resources at local and landscape scales (e.g., floral strips, habitat management) can ensure that bee species have access to forage over the course of their respective activity periods, thus maintaining rich and diverse bee communities. From the bee's perspective, this complementarity pertains to the use of spatially disparate floral resources at different times by the same bee species or genera. This can occur when bees forage between different crops or between a given crop and flowers in the surrounding landscape. Beyond phenological differences 
that give rise to complementary resource use, the concept of "community complementarity" in the floral community suggests that interspecific variation in plant traits (e.g., floral morphology) can engender floral specialization and thus higher levels of diversity in the regional bee community as well (Blüthgen and Klein 2011). This would imply a positive feedback on biodiversity between upper and lower levels in mutualistic networks, such as between plants and pollinators (Fontaine et al. 2005). Spatially heterogeneous resources allow for further niche partitioning among bee species while increasing the impact of diversity on ecosystem functioning (Loreau et al. 2003, Fisher 2016, Venjakob et al. 2016): an example of the spatial insurance hypothesis (Loreau et al. 2003).

To date, many studies have focused on phenological complementarity between individual crops and nearby (semi-) natural habitats (Kennedy et al. 2013). These studies have mostly concerned temperate agroecosystems as opposed to those in the tropics where spatiotemporal availability of food resources is very high. An understudied means for extending floral resource availability for pollinators is the planting of commercial crops that flower in succession (Rao and Stephen 2010). This would benefit bee conservation efforts by providing complementary resources over time and space for long-lived generalist bees (e.g., bumble bees) that forage from multiple crops (Blüthgen and Klein 2011, Shackelford et al. 2013, Rundlöf et al. 2014). On the other hand, if the pollination of a crop were dependent on bees that were short-lived and associated with a specific crop, then temporal complementarity would be less important. The degree to which landscape elements and successively blooming crops complement each other in supporting comparable bee species and genera, or in sustaining regional bee diversity, is not well understood (Garibaldi et al. 2014).

Here, we study wild bee diversity in three pollinatordependent crops that flower in a sequence from mid- to latespring in southern Quebec, Canada: apple orchards (Malus domestica), blueberry (Vaccinium corymbosum) farms, and raspberry (Rubus ideaus) farms. We use field inventories and landscape modelling to address three questions about the role of complementarity in crop blossoming time for sustaining bee populations: (1) Do the three crops exhibit phenological complementarity for bees? (2) Do these crops promote regional bee community diversity through floral specialization? (3) Does landscape-level availability of floral and nesting resources predict bee community composition and diversity across crops? We predict that the three crops will exhibit phenological complementarity by supporting comparable levels of bee diversity (abundance and richness), the same bee species or genera will visit more than one crop, and bee community composition will not differ among the crops. Alternatively, bee species will specialize on only a single crop thus promoting regional bee community diversity. We expect that bee diversity and abundance will be highest in landscapes with diverse habitats for pollinators.

\section{Materials And Methods}

\section{Field site selection}

We studied 20 apple orchards, 18 blueberry fields, and 20 raspberry fields in the Montérégie district of southern
Quebec, Canada (Fig. 1) in 2012. The Montérégie, the second most populated region (1.4 million) in Quebec after Montreal, covers $\sim 11,000 \mathrm{~km}^{2}$ and has high levels of biodiversity for the province (Tardif et al. 2005). A recent shift away from dairy farming to intensive agriculture has led to more annual crops, fewer farms, and increases in chemical interventions (Bélanger and Grenier 2002, Jobin et al. 2010).

The landscape surrounding the study sites was dominated by cropland (e.g., corn and soybean), neighboring apple orchards or deciduous forests. We spaced sites of the same crop at least $1,000 \mathrm{~m}$ apart, beyond the foraging range of most bee species in our area (Greenleaf et al. 2007). To better examine inter-crop complementarity in floral resource provisions for wild bees, we set no minimum distance separating sites with different crops. The three crops were largely phenologically distinct, apples blooming first in mid-May, blueberries in late May, and raspberries in early June. In all cases, our analyses considered possible effects of spatial autocorrelation.

The three crops differ in their requirements for insect pollination: apples cannot set fruit or seed without pollination (Brault and de Oliveira 1995), blueberries are partially parthenocarpic but mostly not self-pollinating (Eck 1988, MacKenzie 1997), while cultivated raspberries are self-fertile (Colbert and De Oliveira 1990). However, for all three crops, pollination is associated with increased fruit set and mass (Delaplane et al. 2000, Cane 2005, Isaacs and Kirk 2010, Sheffield 2014), both of which increase the value of the crop for growers (Garratt et al. 2014). In apple orchards, we focused on McIntosh trees, the leading cultivar in the northeastern United States and eastern Canada (Hampson and Kemp 2003). Small fruit fields included various cultivars of blueberry (Bluecrop, Duke, Elliot, Patriot) and raspberry (Nova, Madawaske). Two of the 18 blueberry growers rented commercially available nests of the common eastern bumble bee (Bombus impatiens). All sites were within flight distance of an orchard that rented honey bees at some point in the spring. All apple orchardists practiced integrative pest management, applying pesticides only when economically justifiable while minimizing risk to human health and the environment. Small fruit growers used low-input management, spraying fungicides and insecticides fewer than six times throughout the season.

\section{Wild bee inventories}

We sampled bees once at each site during the peak bloom of each crop (apple, 11-14 May; blueberry, 29 May-1 June; raspberry, 1-16 June). Our sampling sites within each orchard were $100 \mathrm{~m}$ in length and $50 \mathrm{~m}$ in width, with placement determined by the availability of McIntosh trees in apple orchards and away from field edges in small fruit farms. We observed bees under clear to lightly overcast conditions from 9:00 to 18:00 EST when ambient air temperatures were above $15^{\circ} \mathrm{C}$ and wind speeds $<3.3 \mathrm{~m} / \mathrm{s}$. Environmental covariates including temperature, time of day, relative humidity, and wind speed were recorded at each site using a Kestrel 3500 Pocket Wind Meter (Kestrel Meters, Minneapolis, Minnesota, 


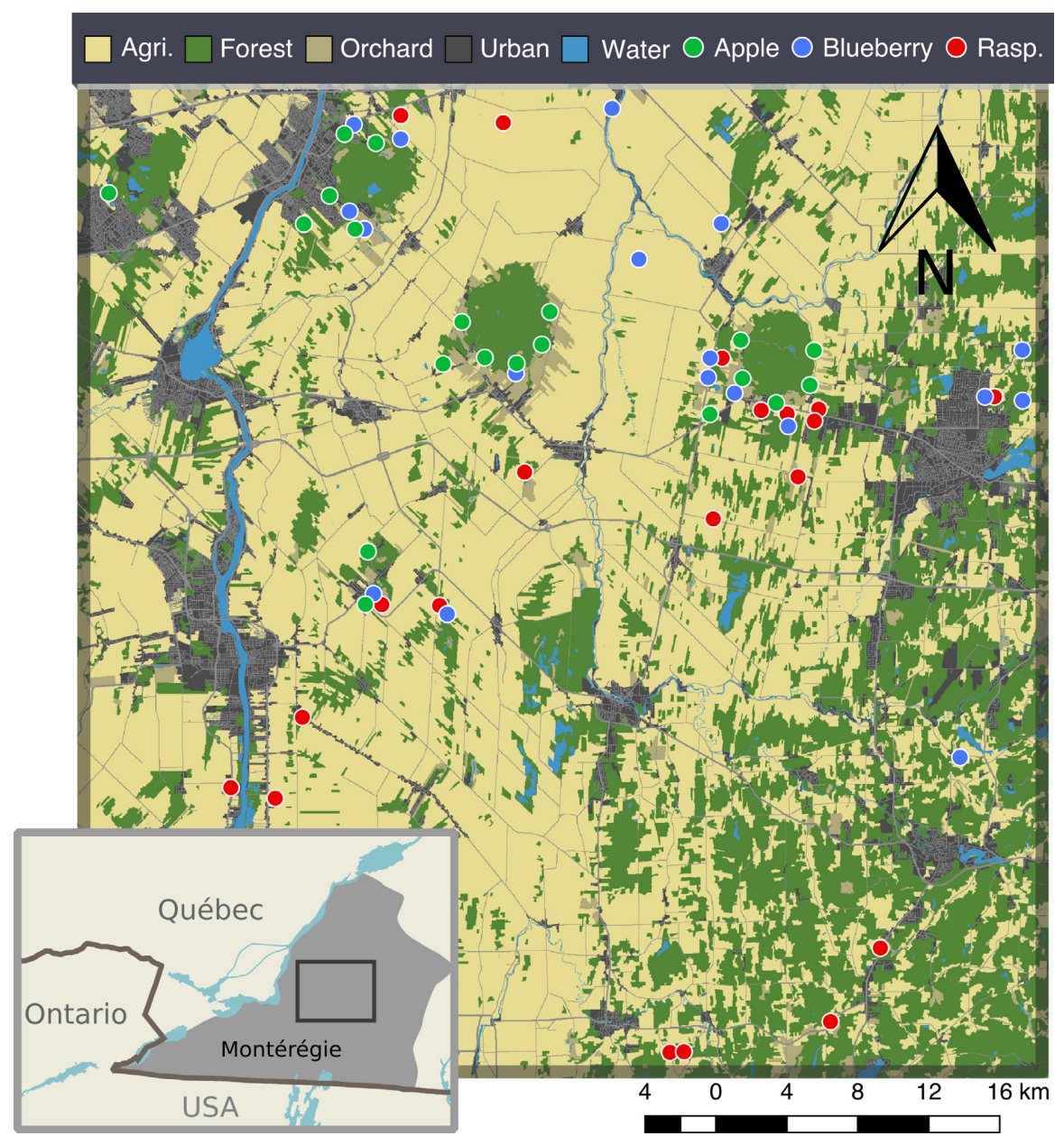

FIG. 1. Map and inset show locations of sampling sites within the broader regional context of southern Quebec, Canada.

USA). To attain suitable weather conditions, raspberry sites had to be sampled over a longer time frame than apple or blueberry.

A single observer sampled bees during $40 \mathrm{~min}$ in apple orchards, while two observers sampled bees during $20 \mathrm{~min}$ in small fruit fields. Observers moved throughout the study site, maintaining a constant pace and sampling flower clusters of the crop as encountered and ignoring other flower species growing along field margins or between rows. To ensure that the entire site was surveyed evenly, they refrained from spending more than five minutes at particularly productive flower patches. Instead, they first surveyed the entire area and then returned to all areas with high levels of bee activity. Honey bees were identified on the fly and tallied using a counter; wild bees were caught with a sweep net, later frozen at the lab and processed for species-level identification.

Captured bees were identified to species or genus using pertinent literature (Mitchell 1960, 1962, Packer et al. 2007, Gibbs 2010) as well as online resources. ${ }^{4}$ Specialists John Ascher, Bryan Danforth, and Jason Gibbs verified species identifications. Voucher specimens are deposited at the Lyman Entomological Museum at McGill University.

\footnotetext{
${ }^{4}$ http://www.Discoverlife.org/
}

\section{Data analysis}

To address our questions and test our set of hypotheses, we measured bee diversity and abundance, analyzed patterns of bee specialization, and explained both bee community composition and diversity with spatial, environmental, and landscape variables. All statistical analyses were conducted with $\mathrm{R}$ version 3.2.3. (R Core Team 2015), ArcMap 10.2.0.3348 (ESRI, Redlands, California, USA) and Python 2.7.6 (Python Software Foundation, Amsterdam, The Netherlands).

Measuring bee diversity.-We used rarefied species richness, wild bee abundance, and the abundance of bees in two important genera (sum of individuals in Andrena or Bombus) as the primary response variables describing bee diversity. These two genera were chosen because of their high prevalence at sites, their proven efficacy in pollinating all three crops (Willmer et al. 1994, Tuell et al. 2009, Martins et al. 2015), and their contrasting life history traits representative of a wide array of bee species in our region (Bombus are long-lived generalists and Andrena short-lived specialists). As the number of bees sampled at each site varied substantially, we corrected our estimates of species richness through rarefaction to standardize sample size across sites (Russo et al. 2015). Following Chao et al. (2014), we 
interpolated values to the minimum number of observations (including all bees, irrespective of their origins) made across sites after having excluded sites with fewer than 10 bee observations; ultimately, only one site was removed prior to the analysis of bee richness. We defined wild bee abundance as the frequency of undomesticated bees visiting a given site, excluding both bumble bees when they were introduced and honey bees in general. Domesticated bumble bees consisted exclusively of worker $B$. impatiens whereas wild bumble bees of the same species were nearly all queens at the time of sampling. Wild and domesticated honey bees could not be distinguished.

Intercrop floral specialization.-We examined the degree to which bee species foraged from all three crops using a bipartite analysis of the network linking bee species with the flowers that they visited (Dormann 2011). From a table of bee species frequencies on each crop, we calculated the Paired Difference Index (PDI) for each species in this network to estimate their degree of generalism (Poisot et al. 2012). The index contrasts the link between a species' most visited floral host against its links with all remaining resources. A high frequency of generalist species in this network (PDI $>0.5$ ) would suggest that the three crops supported comparable bee communities. We tested the significance of PDI values for all species that had at least 20 samples ( 18 of 74 species) by contrasting observed visitations against expectations from a null model using code taken from Dormann (2011). The null model scattered the observed number of interactions over all flowering plant species while keeping the number of links constant and the marginal totals identical to those observed at each site.

We also evaluated the degree to which the bee species in the bipartite network specialized on any of the three crops or their pairwise combinations (e.g., apple-blueberry, appleraspberry, blueberry-raspberry) using an indicator value (IndVal) analysis (Dufrene and Legendre 1997, De Cáceres and Legendre 2009, De Cáceres et al. 2010). The method involved testing the association of each species with all six possible combinations of the three crops to identify species with significant indicator values $(P<0.05)$ after 9,999 random permutations and a Holm correction for multiple tests.

Modeling landscape resource availability.-We approximated landscape-level floral and nesting resource availability by parameterizing the spatially explicit model of wild bee abundance from Lonsdorf et al. (2009), which has been found to effectively predict wild bee diversity across crops (Kennedy et al. 2013). Using information on pollinator nesting resources, floral resources, and foraging distances, this model generates from land cover data an index of relative wild bee abundance at each spatial unit (e.g., $30 \times 30 \mathrm{~m}$ pixel) on the landscape (Lonsdorf et al. 2009, Albert et al. 2017), hereafter referred to as the Landscape Resource Index (LRI). Details on the land cover map and the parameterization process in which each land cover class was attributed floral and nesting suitability scores are summarized in Appendix S3. We tested the robustness of model parameters using a sensitivity analysis in which the foraging distance used to calculate LRI was varied at four "floral extents" (i.e., spatial scales), restricting the available resources within $580 \mathrm{~m}, 830 \mathrm{~m}, 1,330 \mathrm{~m}$, and 2,000 m of site centroids.
Landscape predictors and intercrop patterns of community composition.-We used partial redundancy analysis (RDA; Legendre and Legendre 2012, Oksanen et al. 2015) to examine patterns of bee community compositions across crops (site by bee species occurrence table, including native and nonnative species). This was done while accounting for spatial autocorrelation (Principal Coordinate of Neighbor Matrices [PCNM; Borcard and Legendre 2002] analysis), crop type (apple, blueberry, raspberry), environmental conditions during sampling (relative humidity, temperature, time of day, wind speed), and LRI (separate stepwise model selection for each floral extent). We tested the significance of the best model, each of its constrained axes and each of its terms by permutation $(9,999$ permutations). We used variation partitioning to determine the contribution of each explanatory variable and their interactions to the ordinal space (Peres-Neto et al. 2006), and projected 95\% confidence ellipses for each crop type onto the RDA triplot to illustrate differences in bee community composition. Refer to Appendix S3 for additional details on the testing procedure.

Landscape predictors and intercrop patterns of bee diversity and abundance. - We used linear modelling (GLM) analyses to study how measures of bee diversity (rarefied species richness, total wild bee abundance, Andrena abundance, and Bombus abundance) were influenced by environmental covariates (relative humidity, temperature, time of day, wind speed), crop type (apple, blueberry, raspberry), and LRI. We checked the spatial independence of sites by comparing generalized linear models including all explanatory variables with and without a random effect coding for spatial proximity; the random effect was non-significant in each case (likelihood ratio test $P>0.05$ ) so GLM was used. We also tested the significance of a factor coding for whether the crop was grown in isolation (25 replicates) or paired with one (26 replicates) or two (seven replicates) crops of interest (apple, blueberry, or raspberry) within 1,000 m of sites. Collinearity between variables was verified using variation inflation factors, but ultimately none were removed (Bolker et al. 2009). Bee abundance data were fitted with a negative binomial distribution to control for overdispersion, while rarefied species richness (expressed as non-integer values) was fitted with a Gaussian distribution. Again, model selection was run separately for each GLM of the four floral extents (LRI).

We used the model averaging approach of Johnson and Omland (2004) to study the uncertainty associated with each coefficient. Following Kennedy et al. (2013), we first generated a candidate model set including all possible combinations of the covariates and their respective interactions with crop type, allowing no more than four parameters to avoid overfitting each model. The candidate model set was balanced, in that each covariate appeared 53 times and each interaction term six times, with a total of 134 possible models. We then ranked models according to their AIC values and estimated their Akaike weights and relative importance scores (Barton 2014); the subset of models and their covariates within two AIC units of the best model were retained as a "top model set." The floral extent that resulted in the lowest AIC value overall then was subjected to model averaging. We estimated the model- 
averaged partial regression coefficients of each of the retained covariates in the top model set at the selected spatial scale as well as their $95 \%$ confidence intervals. Covariates were considered important if their summed Akaike weights were above 0.60 and significant if their confidence intervals did not include zero. Models with the lowest AIC values overall were subjected to standard diagnostic testing. This included testing model residuals for spatial-autocorrelation using Moran's I autocorrelation coefficient and visual assessments of sample variograms (Gittleman and Kot 1990, Paradis et al. 2004).

\section{RESULTS}

\section{Field sampling results}

In total, 8,276 bees were observed in apple orchards (2,348 observations), blueberry fields (781), and raspberry fields $(5,147)$, of which 6,601 were honey bees and 1,675 wild bees (Appendix S1: Table S3). Honey bees were most prevalent at raspberry fields (4,344 samples, $84 \%$ of all bees), followed by apple orchards $(2,134 ; 90 \%)$, and blueberry fields $(123 ; 16 \%)$. The proportion of honey bees to wild bees changed from crop to crop (10:1 apples, 1:5 blueberries, 5:1 raspberries). The most abundant wild bee species across crops was B. griseocollis (293 samples), followed by B. bimaculatus (281), and B. impatiens (179). A total of 74 species were observed across 16 genera and five families, the most species rich genus being Andrena (27 species), followed by Lasioglossum (15) and Bombus (8). Excluding honey bees, the most abundant genus at each crop was Andrena in apple orchards (135 samples; $63 \%$ of all wild bees), Bombus in blueberry fields (527; 80\%), and both Bombus (304; 38\%) and Andrena (258; $32 \%$ ) in raspberry fields. Patterns of species level diversity across crops are discussed in the subsection Intercrop floral specialization.

\section{Intercrop floral specialization}

The bipartite network analysis (Table 1, Fig. 2; Appendix S1: Table S3) linking the bees to the crops they visited established that few species are shared among apple orchards and small fruit farms. In fact, only Bombus impatiens, the common eastern bumble bee, exhibited significant levels of floral generalism in this system (PDI 0.46, $P=0.015$ ). The IndVal analysis (Table 1, Fig. 2; Appendix S1: Table S3) also indicated that most bee species inventoried in this study prefer foraging exclusively from either apple, blueberry, or raspberry blossoms. Of the wild bees, only the bumble bee species (B. bimaculatus, $B$. griseocollis, B. impatiens, B. rufocinctus, B. ternarius) forage preferentially from more than one crop, namely raspberries and blueberries. As for honey bees, they were found in high numbers on both apple and raspberry blossoms.

\section{Modeling landscape resource availability}

The optimized nesting and floral suitability scores associated with each land cover class deviated in some instances from our original expectations based on the literature
TABLE 1. Significant indicator species for crops (A, apple; B, blueberry; R, raspberry) and their combinations, as well as their families, Paired Difference Index values (PDI), Indicator Species Values (IndVal), and IndVal $P$ values.

\begin{tabular}{|c|c|c|c|c|}
\hline Family and species & PDI & Crop & IndVal & $P$ \\
\hline \multicolumn{5}{|l|}{ Apidae } \\
\hline Apis mellifera Linnaeus 1758 & 0.74 & AR & 0.99 & 0.005 \\
\hline $\begin{array}{l}\text { Bombus bimaculatus Cresson, } \\
1863\end{array}$ & 0.82 & BR & 0.89 & 0.005 \\
\hline B. griseocollis (DeGeer, 1773) & 0.67 & BR & 0.86 & 0.005 \\
\hline B. impatiens Cresson, 1863 & 0.46 & $\mathrm{BR}$ & 0.81 & 0.005 \\
\hline B. rufocinctus Cresson, 1863 & 0.78 & $\mathrm{BR}$ & 0.61 & 0.01 \\
\hline B. ternarius Say, 1837 & 0.63 & $\mathrm{BR}$ & 0.56 & 0.035 \\
\hline \multicolumn{5}{|l|}{ Halictidae } \\
\hline $\begin{array}{l}\text { Lasioglossum coriaceum } \\
\text { (Smith, 1853) }\end{array}$ & 1.00 & $\mathrm{R}$ & 0.59 & 0.005 \\
\hline \multicolumn{5}{|l|}{ Andrenidae } \\
\hline Andrena bisalicis Viereck, 1908 & 1.00 & $\mathrm{R}$ & 0.59 & 0.01 \\
\hline A. carolina Viereck, 1909 & 1.00 & $\mathrm{~B}$ & 0.67 & 0.005 \\
\hline A. commoda Smith, 1879 & 0.99 & $\mathrm{R}$ & 0.66 & 0.005 \\
\hline A. crataegi Robertson, 1893 & 0.84 & $\mathrm{R}$ & 0.7 & 0.005 \\
\hline A. dunningi Cockerell, 1898 & 1.00 & A & 0.67 & 0.005 \\
\hline A. hippotes Robertson, 1895 & 0.96 & A & 0.48 & 0.015 \\
\hline A. milwaukeensis Graenicher, 1903 & 0.96 & A & 0.64 & 0.005 \\
\hline A. miranda Smith, 1879 & 1.00 & $\mathrm{R}$ & 0.81 & 0.005 \\
\hline A. nivalis Smith, 1853 & 1.00 & $\mathrm{R}$ & 0.45 & 0.03 \\
\hline A. rufosignata Cockerell, 1902 & 1.00 & A & 0.50 & 0.025 \\
\hline A. rugosa Robertson, 1891 & 0.90 & A & 0.65 & 0.005 \\
\hline A. wheeleri Graenicher, 1904 & 1.00 & $\mathrm{R}$ & 0.55 & 0.005 \\
\hline A. wilkella (Kirby, 1802) & 0.93 & $\mathrm{R}$ & 0.69 & 0.005 \\
\hline \multicolumn{5}{|l|}{ Colletidae } \\
\hline Colletes inaequalis Say, 1837 & 1.00 & A & 0.55 & 0.005 \\
\hline \multicolumn{5}{|l|}{ Halictidae } \\
\hline $\begin{array}{l}\text { Lasioglossum quebecense } \\
\text { (Crawford, 1907) }\end{array}$ & 1.00 & A & 0.45 & 0.04 \\
\hline \multicolumn{5}{|l|}{ Apidae } \\
\hline Ceratina calcarata Robertson, 1900 & 1.00 & $\mathrm{R}$ & 0.63 & 0.005 \\
\hline C. mikmaqi Rehan \& Sheffiel, 2011 & 1.00 & $\mathrm{R}$ & 0.77 & 0.005 \\
\hline \multicolumn{5}{|l|}{ Colletidae } \\
\hline Hyleus mesillae (Cockerell, 1896) & 1.00 & $\mathrm{R}$ & 0.45 & 0.035 \\
\hline
\end{tabular}

Notes: Significant PDI values $(P<0.05)$ are shown in boldface type. See Supporting Information for PDI values of remaining bee species.

(Appendix S1: Table S2). Meadows and hedgerows obtained final scores that were higher than initially specified for both nesting and floral resources, and orchards lower than initially expected. Suitability scores for urban areas tended to be higher for floral resources but lower for nesting resources in dense urban areas. Forest had lower scores for nesting resources, especially coniferous forests. Changes in suitability scores for remaining land cover classes had little influence on the fit between predicted and observed wild bee abundances. In general, smaller dispersal distances led to higher correlations between predicted and observed values (Appendix S2: Fig. S1).

\section{Landscape predictors and intercrop patterns of community composition}

None of the PCNM eigenvectors approximating spatial autocorrelation significantly modelled the variance in the 


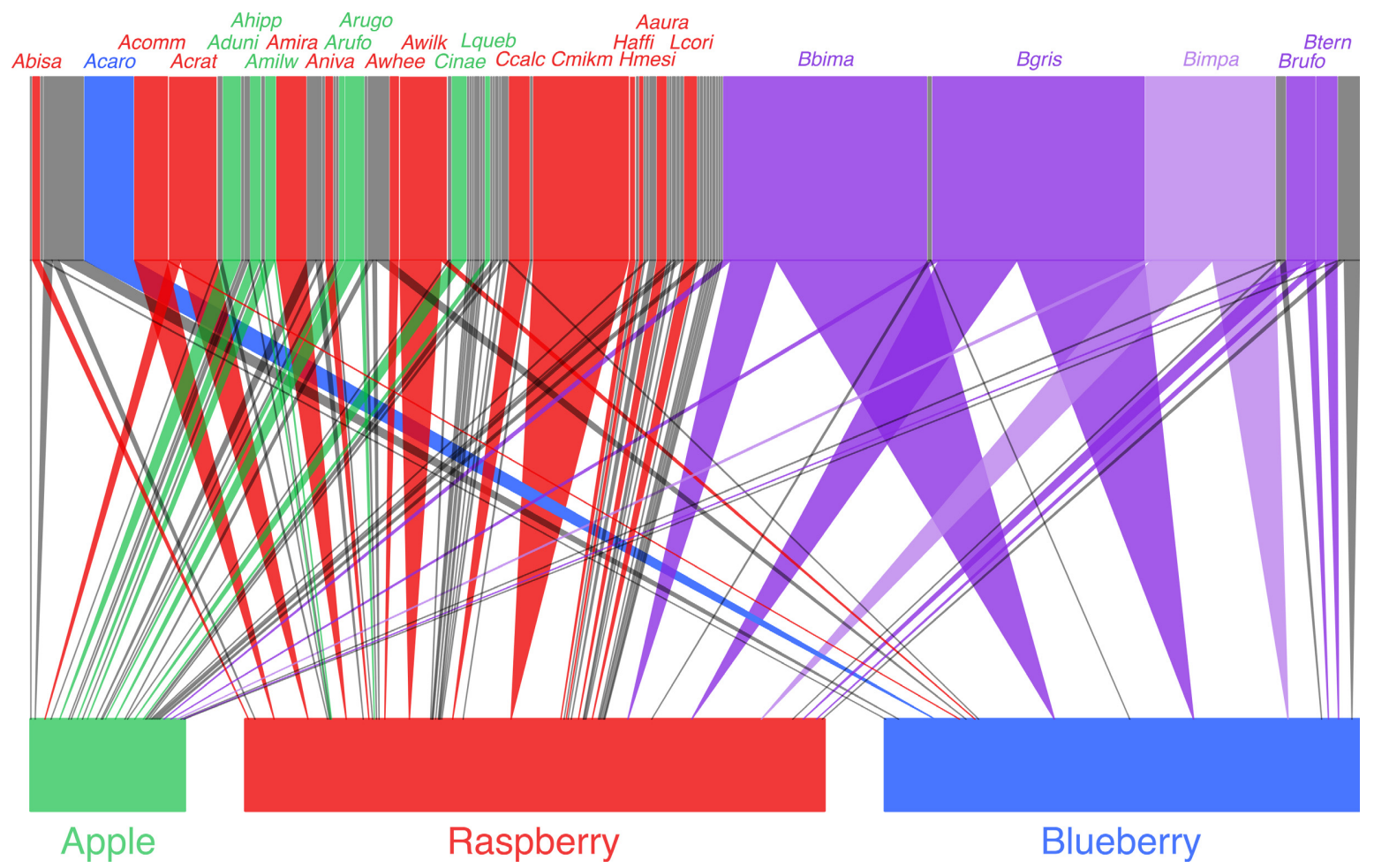

FIG. 2. The network links wild bee species, excluding naturalized honey bees, listed in the upper portion of the figure (c.f. species codes in Appendix S1: Table S3) to the crops (base of the figure) that they visited. The size of each box is scaled to the frequency of a given bee species or the number of visits made to a given crop. The percentage of bee-flower interactions is indicated by the thickness of the connecting lines. Bee species are labeled and color-coded if significantly $(P<0.05)$ associated with (Table 1$)$ apples (red), blueberries (blue), raspberries (red), or both blueberries and raspberries (purple); all remaining species are in gray. Bombus impatiens is highlighted in light purple, as it was a significant associated with blueberries and raspberries in addition to showing significant levels of generalism for the three crops (paired difference index [PDI] $<0.5$; Table 1 ).

site by bee species response matrix $(P>0.05)$, and neither did our quantification of landscape resource availability (LRI). Crop type $\left(R_{\text {adj }}^{2}=0.39, P<0.001\right)$ and temperature $\left(R_{\text {adj }}^{2}=0.004, P=0.031\right)$ were the only significant variables in the best model $\left(R_{\text {adj }}^{2}=0.41, \quad P<0.001\right.$; Fig. 3). None of the variance was shared among these predictor variables. The variance explained by RDA1 $(39 \%$, $P<0.001)$ and $\mathrm{RDA} 2(3 \%, P=0.002)$ was significant. In the resulting triplot (Fig. 3), the effect of temperature is partialled out to focus on the relationship between crop type in the ordinal space. RDA1 polarizes blueberry sites against both raspberry and apple sites, the former being associated with bumble bee species (B. bimaculatus, B. griseocollis, and B. impatiens) and the latter with honey bees. The $95 \%$ confidence ellipses of the sampling sites partitioned by crop type confirm that species-level community composition among the three crops is for the most part distinct.

\section{Landscape predictors and intercrop patterns of bee diversity and abundance}

Model averaging could not be performed for rarefied species richness, wild bee abundance, and bumble bee abundance as, in each case, only a single model was within two AIC units of the top models. Richness was best predicted by LRI at a floral extent of $830 \mathrm{~m}(\beta=0.37 \pm 0.12, t=3.18$,

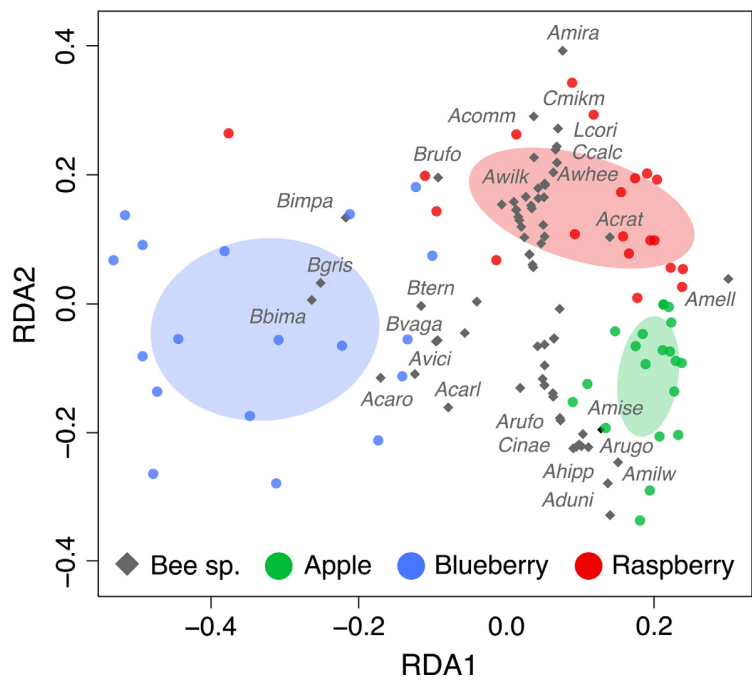

FIG. 3. Redundancy analysis (RDA) triplot showing the distribution of bee species and sites as a function of crop type (ellipses). Species scores have been divided by the standard deviation of each species and multiplied with an equalizing constant. Species with the highest species scores are labeled (see Appendix S1: Table S3 for codes).

$P=0.003), \quad$ temperature $\quad(\beta=0.54 \pm 0.22, \quad t=2.44$, $P=0.018)$, crop type, and the interaction between crop type and temperature (Table 2, Fig. 4; Appendix S2: Fig. S1). 
TABLE 2. The results of model selection including importance values (Imp.), standardized partial regression coefficients $(\beta)$, standard error values (SE), and 95\% confidence intervals (CI) for each predictor variable.

\begin{tabular}{|c|c|c|c|c|c|}
\hline $\begin{array}{l}\text { Response and predictor } \\
\text { variables }\end{array}$ & Imp. & $\beta$ & $\mathrm{SE}$ & $\begin{array}{l}\text { Lower } \\
\text { CI }\end{array}$ & $\begin{array}{l}\text { Upper } \\
\text { CI }\end{array}$ \\
\hline \multicolumn{6}{|l|}{ Species richness } \\
\hline LRI (830 m) & & 0.37 & 0.12 & 0.14 & 0.60 \\
\hline Temp. & & 0.54 & 0.22 & 0.10 & 0.99 \\
\hline Temp. $\times$ Blueberry & & -0.19 & 0.28 & -0.75 & 0.38 \\
\hline Blueberry & & 0.80 & 0.29 & 0.21 & 1.39 \\
\hline Temp. $\times$ Raspberry & & -0.97 & 0.29 & -1.56 & -0.38 \\
\hline Raspberry & & 0.66 & 0.31 & 0.03 & 1.29 \\
\hline \multicolumn{6}{|l|}{ Wild bee abundance } \\
\hline LRI (580 m) & & 0.26 & 0.07 & 0.13 & 0.40 \\
\hline Temp. & & 0.62 & 0.16 & 0.32 & 0.93 \\
\hline Blueberry & & 1.11 & 0.18 & 0.77 & 1.46 \\
\hline Temp. $\times$ Blueberry & & -0.60 & 0.19 & -0.97 & -0.24 \\
\hline Raspberry & & 1.47 & 0.19 & 1.09 & 1.85 \\
\hline Temp. $\times$ Raspberry & & -0.89 & 0.19 & -1.26 & -0.52 \\
\hline \multicolumn{6}{|l|}{ Bumble bee abundance } \\
\hline LRI (580 m) & & 0.35 & 0.10 & 0.16 & 0.55 \\
\hline Temperature & & 0.02 & 0.26 & -0.51 & 0.56 \\
\hline Blueberry & & 2.98 & 0.28 & 2.43 & 3.56 \\
\hline Temp. $\times$ Blueberry & & -0.12 & 0.29 & -0.71 & 0.46 \\
\hline Raspberry & & 2.48 & 0.30 & 1.90 & 3.10 \\
\hline Temp. $\times$ Raspberry & & -1.33 & 0.32 & -1.97 & -0.72 \\
\hline \multicolumn{6}{|l|}{ Mining bee abundance } \\
\hline Temperature & 1 & 0.56 & 0.16 & 0.24 & 0.88 \\
\hline Raspberry & 1 & 0.49 & 0.37 & -0.23 & 1.21 \\
\hline Blueberry & 1 & -0.76 & 0.41 & -1.57 & 0.05 \\
\hline LRI (580 m) & 0.79 & 0.42 & 0.20 & 0.03 & 0.81 \\
\hline Time of Day & 0.73 & -0.18 & 0.34 & -0.85 & 0.49 \\
\hline LRI $\times$ Raspberry & 0.27 & -0.26 & 0.31 & -0.88 & 0.35 \\
\hline LRI $\times$ Blueberry & 0.27 & 0.61 & 0.38 & -0.13 & 1.35 \\
\hline $\begin{array}{l}\text { Time of Day } \times \\
\text { Raspberry }\end{array}$ & 0.21 & -0.49 & 0.35 & -1.17 & 0.20 \\
\hline $\begin{array}{l}\text { Time of Day } \times \\
\text { Blueberry }\end{array}$ & 0.21 & -1.33 & 0.39 & -2.09 & -0.56 \\
\hline
\end{tabular}

Notes: Significant values (CI not including zero) are shown in boldface type; importance values could not be calculated for bee richness, wild bee abundance, and bumble bee abundance because only a single model was included in the top model set $(\triangle \mathrm{AIC}<2)$. Only variables in the top model sets are given. LRI, land resource index; temp. temperature. A factor coding for "apple orchard site" was used as the reference group to minimize the size of the table; see section Landscape predictors and intercrop patterns of bee diversity and abundance for results specific to apple orchards.

Bee species richness in blueberry fields $(\beta=0.80 \pm 0.29$, $t=2.73, P=0.009)$ and raspberry fields $(\beta=0.65 \pm 0.31$, $t=2.11, P=0.04)$ was significantly higher than that in apple orchards, but richness in blueberry and raspberry fields was the same on average $(\beta=0.14 \pm 0.28, t=0.51$, $P=0.61)$. The positive relationship between richness and temperature was significantly less pronounced in raspberry fields $(\beta=-0.97 \pm 0.29, t=-3.32, P=0.002)$ than in apple orchards or blueberry fields.

Wild bee abundance was best predicted by LRI at a floral extent of $580 \mathrm{~m}(\beta=0.26 \pm 0.07, z=3.86, P<0.001)$, temperature $(\beta=0.62 \pm 0.16, z=3.91, P<0.001)$, crop type, and the interaction between crop type and temperature (Table 2, Fig. 4; Appendix S2: Fig. S2). It was significantly higher in blueberry fields $(\beta=1.11 \pm 0.18$, $z=6.31, P<0.001)$ and raspberry fields $(\beta=1.47 \pm 0.19$, $z=7.84, P<0.001)$ than in apple orchards. Bee abundance in raspberry fields was significantly higher than in blueberry fields $(\beta=0.36 \pm 0.16, z=-2.25, P=0.02)$. The positive relationship between bee abundance and temperature was significantly less pronounced in blueberry fields $(\beta=-0.60 \pm 0.19, \quad z=3.20, \quad P=0.001)$ and raspberry fields $(\beta=-0.89 \pm 0.19, z=-4.59, P<0.001)$ than in apple orchards.

Bumble bee abundance was significantly higher in blueberry $(\beta=2.98 \pm 0.28, z=10.53, P<0.001)$ and raspberry fields $(\beta=2.48 \pm 0.30, z=8.26, P<0.001)$ than in apple orchards; abundance in blueberry fields was also higher than in raspberry fields $(\beta=0.50 \pm 0.20, z=2.51, P=0.01)$ (Table 2, Fig. 4; Appendix S2: Fig. S1). LRI at a floral extent of $580 \mathrm{~m}$ best predicted bumble bee abundance $(\beta=0.35 \pm 0.10, z=3.59, P<0.001)$. The positive relationship between bumble bee abundance and temperature was significantly less pronounced in raspberry fields $(\beta=-1.33 \pm 0.32, z=-4.23, P<0.001)$.

Mining bee (Andrena) abundance was significantly lower in blueberry fields (importance value (Imp.) $=1.00$, $\beta=-1.25 \pm 0.36$ ) than in raspberry fields, but their abundance in either raspberry fields or blueberry fields did not differ from that in apple orchards (Table 2, Fig. 4; Appendix S2: Fig. S1). Their numbers were also driven by temperature $(\operatorname{Imp} .=1.00, \quad \beta=0.56 \pm 0.16)$ and LRI (Imp. $=0.79, \beta=0.42 \pm 0.20$ ).

\section{DisCUSSION}

We compared bee diversity across mass-flowering crops that bloom in sequence while assessing the importance of surrounding nesting and floral resource availability. Bee diversity at apple orchards and small fruit farms was highest when diverse and abundant nesting and floral resources were available in the surrounding landscape. Crops exhibited phenological complementarity by sustaining certain bee genera (Andrena and Bombus) throughout the spring but few bee species visited more than one crop. Our approach mirrors that of Mandelik et al. (2012) and Mallinger et al. (2016) in its appraisal of complementary habitat use by bees to understand how they persist in a humanaltered landscape. However, like Winfree et al. (2008) and Adamson et al. (2012), our focus is on intercrop visitation patterns of wild bee species that can inform regional pollinator conservation initiatives and the cropping strategies employed by agriculturalists. We extend previous work by comparing both intercrop and landscape-level complementarities in bee resource provisions, while also assessing community turnover across our study region.

\section{Do apple, blueberry, and raspberry crops exhibit phenological complementarity for bees?}

At the bee species level, apple orchards, blueberry fields, and raspberry fields did not demonstrate phenological complementarity since they supported distinct bee communities in our study system, as also reported by Adamson et al. (2012). In fact, only a single bee species, the common eastern 

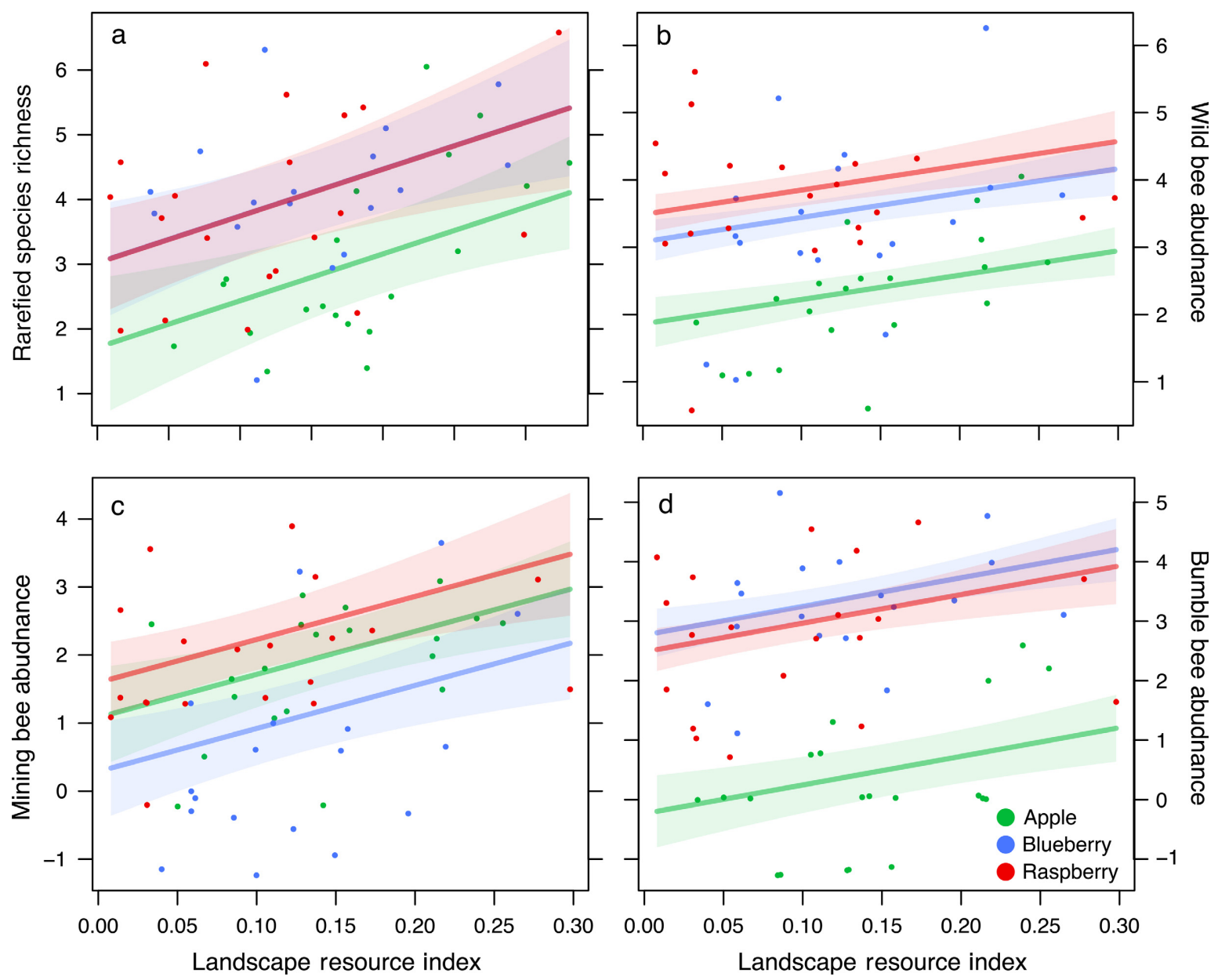

FIG. 4. Partial effects graphs showing the relationship between (a) rarefied species richness, (b) wild bee abundance, (c) mining bee abundance, and (d) bumble bee abundance as a function of landscape resource index (LRI) at apple orchards and small fruit fields. The models have been scaled to bring out the linear relationship between predictor and response variables. Full models are described in Table 2. Land resource index (LRI) was calculated at a floral extent distance of $830 \mathrm{~m}$ for species richness (a) and $580 \mathrm{~m}$ for all other models (b-d).

bumble bee (B. impatiens), foraged from all three crops in large numbers. Even the spatial proximity or presence of neighboring orchards and small fruit fields could not predict bee community composition as well as could crop type alone. This likely reflects the turnover of bee activity periods as well as interspecific floral preferences.

Apple orchards, blueberry fields, and raspberry fields did demonstrate phenological complementarity at the genus level, sustaining wild bumble bees (Bombus) and mining bees (Andrena) that foraged from at least two of the crops. Moreover, bee richness and wild bee abundance in raspberry and blueberry sites were comparable, both being higher than that in apple orchards. Despite the brief period during which the three crops flower in sequence, this result may reflect phenology as sufficient time has elapsed for some bee taxa (e.g., bumble bees) to grow in numbers and build their colonies by the time small fruit fields bloom. Since apple orchard area is negatively associated with bee diversity in our region (Martins et al. 2015), the smaller size of small fruit fields may also influence results as the demand for wild pollinators likely scales with forage supply.
Mining bees specialize on the rosaceous pollen (Gardner and Ascher 2006) of apple and raspberry blossoms while the preference of bumble bees for the ericaceous pollen of blueberry flowers is well documented (Desjardins and De Oliveira 2006, Moisan-Deserres et al. 2014). Bumble bees are also likely attracted by the rich nectar rewards of raspberry blossoms (Simidchiev 1976), as many species in our study specialized on and are effective pollinators of both raspberry and blueberry flowers (Willmer et al. 1994, Tuell et al. 2009). Diverse nectar and pollen sources may enhance the nutrient balance and health of bees, but research to date has focused only on honey bees (Roulston and Cane 2000). Raspberry is an ideal complement to both apple and blueberry as it supports bee genera found in the other crops. Raspberry also blossoms for the longest period of time, well into the late summer when many other mass-flowering crops and natural habitats (e.g., deciduous forests) in our region are depauperate in floral resources (Whitney 1984). Raspberry crops potentially can reduce year-to-year variance in bee population abundance as the availability of late season forage positively predicts bumble bee colony success the following spring (Rundlöf et al. 2014). 
The abundance of mining and bumble bees is relevant not only to pollinator conservation, but also crop pollination and fruit production. For example, mining bees are abundant in apple orchards and deposit more pollen per visit than other bees, but are relatively slow moving; bumble bees are infrequent, but visit many more blossoms per minute than mining bees (Park et al. 2016). From the plant's perspective, a combination of mining bees and bumble bees maximizes both the delivery and quality of apple pollination (Martins et al. 2015). In the case of both apple orchards and small fruit fields, wild bees (e.g., bumble bees) compensate for the inactivity of domesticated honey bees during inclement weather conditions (Rogers et al. 2014, Martins et al. 2015) and for their inefficiency as pollinators (Willmer et al. 1994, Javorek et al. 2002, Park et al. 2016). However, importing honey bee colonies to farms can offset year to year variance in natural bee populations (Delaplane et al. 2000) and may be required to satisfy commercially relevant levels of pollination (Isaacs and Kirk 2010). Planting apple, blueberry, and raspberry at the farmstead and landscape scales can potentially promote fruit yield by sustaining functionally diverse bee communities, but this has yet to be verified empirically.

\section{Do apple, blueberry, and raspberry crops promote regional bee community diversity through floral specialization?}

Each of the three crops or combinations thereof (e.g., blueberry and raspberry) exhibited high degrees of floral specialization by bee species. These results may reflect turnover in bee activity periods during the spring, as our study did not attempt to control for interspecific differences in bee phenology. Consistent with Gardner and Ascher (2006), specialists on apple blossoms tended to include Andrena and Colletes spp. that are active early in the spring and prefer rosaceous pollen. Andrena carolina, a known Vaccinium specialist (Tuell et al. 2009) and abundant in blueberry fields in northern Quebec (Moisan-Deserres et al. 2014), was prevalent at blueberry sites with local features favorable to ground-nesting bees such as sandy soil and exposed field margins. As previously mentioned, bumble bees typically foraged on blueberry and raspberry blossoms. Finally, raspberry supported a high diversity of stem (e.g., Ceratina spp.) and social ground nesting (e.g., Lasioglossum) bees. Ceratina spp. are known to nest in raspberry canes (Vickruck et al. 2011) and were observed doing so at our field sites. Lasioglossum spp. were also abundant in raspberry fields studied by Adamson et al. (2012) in Virginia, USA. These results suggest that agricultural management that promotes the intercropping of apples, blueberries and raspberries should support bee diversity both in terms of local and regional bee community diversity. Further research is needed to compare the degree of complementarity of these three crops with others that bloom sequentially or at the same time, such as tomato and squash.

\section{Does landscape-level availability of complementary floral and nesting resources predict bee community composition and diversity across crops?}

Diverse and abundant nesting and floral resources in the surrounding landscape promoted bee diversity at apple orchards and small fruit farms. This was true at a spatial scale typical of bee foraging distances and the one used to previously study the landscape ecology of bee diversity (Martins et al. 2015, Koh et al. 2016). The Landscape Resource Index (LRI) was a better predictor of bee diversity and abundance than the presence of nearby orchards or small fruit fields, suggesting that resource availability beyond the orchard context is more important than adjacency of complementary flowering crops. As has been found through global meta-analysis (Kennedy et al. 2013), the relationship between LRI and bee diversity and abundance was the same across the three crops despite each being exploited by distinct bee communities. We add to their work by assessing a region (southern Quebec) and a crop (raspberry) that had not been covered in their analysis. From our results, we infer that the spatial complementarity of floral and nesting resources is critical to sustaining bee populations in our study region.

In parameterizing our model, we identified landscape features essential for bees in apple orchards and small fruit fields including meadows, hedgerows, and low-density urban areas (e.g., suburbs). Notably, bees track floral resources from hedgerows to meadows in southern Quebec as they have complementary floral phenologies (Payette and De Oliveira 1989); hedgerows are characterized by shrubs that blossom in the spring (e.g., Salix discolor, Amelanchier spp., Prunus spp.), and meadows by forbs that blossom in the mid to late summer (e.g., Trifolium spp., Vicia cracca, Melilotus alba, Solidago spp.). In New Jersey and Pennsylvania, USA, similar phenological synchrony was observed between agricultural lots and old fields (Mandelik et al. 2012). Hedgerows also act as windbreaks, promoting homogeneous distribution of wild pollinators in blueberry fields (MoisanDeSerres et al. 2015), as well as corridors for bee dispersal (Cranmer et al. 2012). Similarly, conditions favorable for pollinators in urban settings pertain to continuous floral and nesting resource levels in residential gardens and parks (Fetridge et al. 2008, Osborne et al. 2008, BanaszakCibicka et al. 2016, Martins et al. 2017), low pesticide levels (Lawrence et al. 2016, Botías et al. 2017), heterogeneity in land cover (Senapathi et al. 2015), and warmer temperatures induced by the heat island effect (Banaszak-Cibicka 2014). It is reasonable to consider meadows, hedgerows and suburbs as sources of native bees for adjacent crop fields (Goulson et al. 2010, Morandin and Kremen 2013, Sheffield et al. 2013).

\section{CONCLUSION}

Managing apple orchards and small fruit fields to maximize their spatiotemporal asynchrony can help to conserve bees while securing fruit pollination. This would provide spatial insurance for bee diversity, pollination functioning and ecosystem services within the landscape (Loreau et al. 2003). In our study system, each crop complements the others in their flowering phenology to sustain important wild pollinators, regional community diversity and a total of 74 bee species. Ensuring the availability of floral and nesting resources beyond the orchard context in the surrounding landscape is critical to ecosystem services provisions by wild pollinators. Our findings underscore the 
importance of an integrated conservation approach for wild pollinators and sustained pollination services including diversified cropping strategies and protecting meadows and hedgerows in agroecosystems, as well as improving the quality of suburban habitats for bees. Developing an integrated conservation approach on these lines will require refining the spatial resolution of the underlying landscape processes (Lonsdorf et al. 2009), parsing the landscape classes to better reflect plant species distributions (Koh et al. 2016) and bee nesting habitats (Sardinas and Kremen 2014), studying inter-year variance in pollinator turnover across crops, investigating phenological complementarity between crops that blossom simultaneously and factoring in the effects of pesticide exposure (Park et al. 2015).

\section{ACKNOWLedgments}

We gratefully acknowledge the Natural Science and Engineering Research Council of Canada, the Fonds de Recherche Nature et Technologies Québec, the Quebec Centre for Biodiversity Science and the Fédération des Producteurs de Pommes du Québec for funding and support. A. Gonzalez was supported by the Canada Research Chair program, a Killam Fellowship and the Liber Ero Chair in Conservation Biology. We thank the apple, blueberry, and raspberry growers in the Montérégie for their willingness to provide access to their orchards; McGill University for permission to work at the Gault Nature Reserve; Julien Massé- Jodoin, Natasha Salter, and Sarah Saldahna for field assistance; John Ascher, Bryan Danforth, and Jason Gibbs for their help with insect identification; and Maria Dumitru for assisting with GIS data. This work contributes to the Labex OT-Med (no. ANR-11-LABX-0061) funded by the French Government through the A*MIDEX project (no. ANR-11IDEX-0001-02).

\section{Literature Cited}

Adamson, N. L., T. H. Roulston, R. D. Fell, and D. E. Mullins. 2012. From April to August-wild bees pollinating crops through the growing season in Virginia, USA. Environmental Entomology 41:813-821.

Albert, C. H., B. Rayfield, M. Dumitru, and A. Gonzalez. 2017. Applying network theory to prioritize multi-species habitat networks that are robust to climate and land-use change. Conservation Biology 31:1383-1396.

Albrecht, M., B. Schmid, Y. Hautier, and C. B. Müller. 2012. Diverse pollinator communities enhance plant reproductive success. Proceedings of the Royal Society B 279:4845-4852.

Banaszak-Cibicka, W. 2014. Are urban areas suitable for thermophilic and xerothermic bee species (Hymenoptera: Apoidea: Apiformes)? Apidologie 45:145-155.

Banaszak-Cibicka, W., H. Ratyńska, and Ł. Dylewski. 2016. Features of urban green space favourable for large and diverse bee populations (Hymenoptera: Apoidea: Apiformes). Urban Forestry and Urban Greening 20:448-452.

Bartomeus, I., J. S. Ascher, J. Gibbs, B. N. Danforth, D. L. Wagner, S. M. Hedtke, and R. Winfree. 2013. Historical changes in northeastern US bee pollinators related to shared ecological traits. Proceedings of the National Academy of Sciences USA 110: 4656-4660.

Bartomeus, I., S. G. Potts, I. Steffan-Dewenter, B. E. Vaissiere, M. Woyciechowski, K. M. Krewenka, T. Tscheulin, S. P. Roberts, H. Szentgyörgyi, and C. Westphal. 2014. Contribution of insect pollinators to crop yield and quality varies with agricultural intensification. PeerJ 2:e328.

Bartoń, K. 2014. MuMIn: multi-model inference. R package version 1.10.5. http://CRAN.R-project.org/package=MuMIn
Bélanger, L., and M. Grenier. 2002. Agriculture intensification and forest fragmentation in the St. Lawrence valley, Québec, Canada. Landscape Ecology 17:495-507.

Blitzer, E. J., J. Gibbs, M. G. Park, and B. N. Danforth. 2016. Pollination services for apple are dependent on diverse wild bee communities. Agriculture, Ecosystems \& Environment 221:1-7.

Blüthgen, N., and A.-M. Klein. 2011. Functional complementarity and specialisation: the role of biodiversity in plant-pollinator interactions. Basic and Applied Ecology 12:282-291.

Bolker, B. M., M. E. Brooks, C. J. Clark, S. W. Geange, J. R. Poulsen, M. H. H. Stevens, and J.-S. S. White. 2009. Generalized linear mixed models: a practical guide for ecology and evolution. Trends in Ecology and Evolution 24:127-135.

Borcard, D., and P. Legendre. 2002. All-scale spatial analysis of ecological data by means of principal coordinates of neighbour matrices. Ecological Modelling 153:51-68.

Botías, C., A. David, E. M. Hill, and D. Goulson. 2017. Quantifying exposure of wild bumblebees to mixtures of agrochemicals in agricultural and urban landscapes. Environmental Pollution 222:7382.

Brault, A.-M., and D. de Oliveira. 1995. Seed number and an asymmetry index of McIntosh Apples. HortScience 30:44-46.

Brittain, C., N. Williams, C. Kremen, and A.-M. Klein. 2013. Synergistic effects of non-Apis bees and honey bees for pollination services. Proceedings of the Royal Society B 280:20122767.

Burkle, L. A., J. C. Marlin, and T. M. Knight. 2013. Plant-pollinator interactions over 120 years: loss of species, co-occurrence, and function. Science 339:1611-1615.

Cane, J. H. 2005. Pollination potential of the bee Osmia aglaia for cultivated red raspberries and blackberries (Rubus: Rosaceae). HortScience 40:1705-1708.

Carvalheiro, L. G., W. E. Kunin, P. Keil, J. Aguirre-Gutiérrez, W. N. Ellis, R. Fox, Q. Groom, S. Hennekens, W. Landuyt, and D. Maes. 2013. Species richness declines and biotic homogenisation have slowed down for NW-European pollinators and plants. Ecology Letters 16:870-878.

Chao, A., N. J. Gotelli, T. Hsieh, E. L. Sander, K. Ma, R. K. Colwell, and A. M. Ellison. 2014. Rarefaction and extrapolation with Hill numbers: a framework for sampling and estimation in species diversity studies. Ecological Monographs 84:45-67.

Colbert, S., and D. De Oliveira. 1990. Influence of pollen variety on raspberry (Rubus idaeus L.) development. Journal of Heredity 81:434-437.

Cranmer, L., D. McCollin, and J. Ollerton. 2012. Landscape structure influences pollinator movements and directly affects plant reproductive success. Oikos 121:562-568.

De Cáceres, M., and P. Legendre. 2009. Associations between species and groups of sites: indices and statistical inference. Ecology 90:3566-3574.

De Cáceres, M., P. Legendre, and M. Moretti. 2010. Improving indicator species analysis by combining groups of sites. Oikos 119:1674-1684.

Delaplane, K. S., D. R. Mayer, and D. F. Mayer. 2000. Crop pollination by bees. CABI Publishing, New York, New York, USA.

Desjardins, Ė.-C., and D. De Oliveira. 2006. Commercial bumble bee Bombus impatiens (Hymenoptera: Apidae) as a pollinator in lowbush blueberry (Ericale: Ericaceae) fields. Journal of Economic Entomology 99:443-449.

Dormann, C. F. 2011. How to be a specialist? Quantifying specialisation in pollination networks. Network Biology 1:1-20.

Dufrene, M., and P. Legendre. 1997. Species assemblages and indicator species: the need for a flexible asymmetrical approach. Ecological Monographs 67:345-366.

Eck, P. 1988. Blueberry science. Rutgers University Press, New Brunswick, New Jersey, USA.

Fetridge, E. D., J. S. Ascher, and G. A. Langellotto. 2008. The bee fauna of residential gardens in a suburb of New York City (Hymenoptera: Apoidea). Annals of the Entomological Society of America 101:1067-1077. 
Fisher, K. 2016. Phenological floral resource complementarity is important for bee abundance. University of Michigan, Ann Arbor, Michigan, USA.

Fontaine, C., I. Dajoz, J. Meriguet, and M. Loreau. 2005. Functional diversity of plant-pollinator interaction webs enhances the persistence of plant communities. PLoS Biology 4:e1.

Gardner, K. E., and J. S. Ascher. 2006. Notes on the native bee pollinators in New York apple orchards. Journal of the New York Entomological Society 114:86-91.

Garibaldi, L. A., I. Steffan-Dewenter, C. Kremen, J. M. Morales, R. Bommarco, S. A. Cunningham, L. G. Carvalheiro, N. P. Chacoff, J. H. Dudenhoeffer, and S. S. Greenleaf. 2011. Stability of pollination services decreases with isolation from natural areas despite honey bee visits. Ecology Letters 14:1062-1072.

Garibaldi, L. A., I. Steffan-Dewenter, R. Winfree, M. A. Aizen, R. Bommarco, S. A. Cunningham, C. Kremen, L. G. Carvalheiro, L. D. Harder, and O. Afik. 2013. Wild pollinators enhance fruit set of crops regardless of honey bee abundance. Science 339:16081611.

Garibaldi, L. A., L. G. Carvalheiro, S. D. Leonhardt, M. A. Aizen, B. R. Blaauw, R. Isaacs, M. Kuhlmann, D. Kleijn, A. M. Klein, and C. Kremen. 2014. From research to action: enhancing crop yield through wild pollinators. Frontiers in Ecology and the Environment 12:439-447.

Garratt, M. P. D., T. D. Breeze, N. Jenner, C. Polce, J. C. Biesmeijer, and S. G. Potts. 2014. Avoiding a bad apple: Insect pollination enhances fruit quality and economic value. Agriculture, Ecosystems \& Environment 184:34-40.

Gibbs, J. 2010. Revision of the metallic species of Lasioglossum (Dialictus) in Canada (Hymenoptera, Halictidae, Halictini). Zootaxa 2591:1-382.

Gittleman, J. L., and M. Kot. 1990. Adaptation: statistics and a null model for estimating phylogenetic effects. Systematic Biology 39:227-241.

Goulson, D., G. C. Lye, and B. Darvill. 2008. Decline and conservation of bumble bees. Annual Review of Entomology 53:191-208.

Goulson, D., O. Lepais, S. O'Connor, J. L. Osborne, R. A. Sanderson, J. Cussans, L. Goffe, and B. Darvill. 2010. Effects of land use at a landscape scale on bumblebee nest density and survival. Journal of Applied Ecology 47:1207-1215.

Greenleaf, S. S., N. M. Williams, R. Winfree, and C. Kremen. 2007. Bee foraging ranges and their relationship to body size. Oecologia 153:589-596.

Haaland, C., R. E. Naisbit, and L. F. Bersier. 2011. Sown wildflower strips for insect conservation: a review. Insect Conservation and Diversity 4:60-80.

Hampson, C. R., and H. Kemp. 2003. Characteristics of important commercial apple cultivars. Pages $61-89$ in D. C. Ferree and I. J. Warrington, editors. Apples: Botany, production and uses. CABI Publishing, Cambridge, UK.

Hoehn, P., T. Tscharntke, J. M. Tylianakis, and I. Steffan-Dewenter 2008. Functional group diversity of bee pollinators increases crop yield. Proceedings of the Royal Society B 275:2283-2291.

Isaacs, R., and A. K. Kirk. 2010. Pollination services provided to small and large highbush blueberry fields by wild and managed bees. Journal of Applied Ecology 47:841-849.

Javorek, S. K., K. E. Mackenzie, and S. P. Vander Kloet. 2002. Comparative pollination effectiveness among bees (Hymenoptera: Apoidea) on lowbush blueberry (Ericaceae: Vaccinium angustifolium). Annals of the Entomological Society of America 95:345351.

Jobin, B., C. Latendresse, M. Grenier, C. Maisonneuve, and A. Sebbane. 2010. Recent landscape change at the ecoregion scale in Southern Québec (Canada), 1993-2001. Environmental Monitoring and Assessment 164:631-647.

Johnson, J. B., and K. S. Omland. 2004. Model selection in ecology and evolution. Trends in Ecology \& Evolution 19:101-108.

Kennedy, C. M., E. Lonsdorf, M. C. Neel, N. M. Williams, T. H. Ricketts, R. Winfree, R. Bommarco, C. Brittain, A. L. Burley, and D. Cariveau. 2013. A global quantitative synthesis of local and landscape effects on wild bee pollinators in agroecosystems. Ecology Letters 16:584-599.

Kevan, P. G., E. A. Clark, and V. G. Thomas. 1990. Insect pollinators and sustainable agriculture. American Journal of Alternative Agriculture 5:13-22.

Klein, A.-M., C. Müller, P. Hoehn, and C. Kremen. 2009. Understanding the role of species richness for crop pollination services. Pages 195-208 in D. E. B. S. Naeem, A. Hector, M. Loreau, and C. Perrings, editors. Biodiversity, ecosystem function and human wellbeing. Oxford University Press, New York, New York, USA.

Koh, I., E. V. Lonsdorf, N. M. Williams, C. Brittain, R. Isaacs, J. Gibbs, and T. H. Ricketts. 2016. Modeling the status, trends, and impacts of wild bee abundance in the United States. Proceedings of the National Academy of Sciences USA 113:140-145.

Kremen, C., N. M. Williams, M. A. Aizen, B. Gemmill-Herren, G. LeBuhn, R. Minckley, L. Packer, S. G. Potts, I. Steffan-Dewenter, and D. P. Vázquez. 2007. Pollination and other ecosystem services produced by mobile organisms: a conceptual framework for the effects of land-use change. Ecology Letters 10:299-314.

Lawrence, T., E. Culbert, A. Felsot, V. Hebert, and W. Sheppard. 2016. Survey and risk assessment of Apis mellifera (Hymenoptera: Apidae) exposure to neonicotinoid pesticides in urban, rural, and agricultural settings. Journal of Economic Entomology 109:520 528.

Legendre, P., and L. F. Legendre. 2012. Numerical ecology. Third edition. Elsevier, Amsterdam, The Netherlands.

Lonsdorf, E., C. Kremen, T. Ricketts, R. Winfree, N. Williams, and S. Greenleaf. 2009. Modelling pollination services across agricultural landscapes. Annals of Botany 103:1589-1600.

Loreau, M., N. Mouquet, and A. Gonzalez. 2003. Biodiversity as spatial insurance in heterogeneous landscapes. Proceedings of the National Academy of Sciences USA 100:12765-12770.

MacKenzie, K. E. 1997. Pollination requirements of three highbush blueberry (Vaccinium corymbosum L.) cultivars. Journal of the American Society for Horticultural Science 122:891-896.

Mallinger, R. E., and C. Gratton. 2015. Species richness of wild bees, but not the use of managed honeybees, increases fruit set of a pollinator-dependent crop. Journal of Applied Ecology 52:323330.

Mallinger, R. E., J. Gibbs, and C. Gratton. 2016. Diverse landscapes have a higher abundance and species richness of spring wild bees by providing complementary floral resources over bees' foraging periods. Landscape Ecology 31:1523-1535.

Mandelik, Y., R. Winfree, T. Neeson, and C. Kremen. 2012. Complementary habitat use by wild bees in agro-natural landscapes. Ecological Applications 22:1535-1546.

Martins, K. T., A. Gonzalez, and M. J. Lechowicz. 2015. Pollination services are mediated by bee functional diversity and landscape context. Agriculture Ecosystems Environment 200:12-20.

Martins, K. T., A. Gonzalez, and M. J. Lechowicz. 2017. Patterns of pollinator turnover and increasing diversity associated with urban habitats. Urban Ecosystems 20:1-13.

Mitchell, T. 1960. Bees of the eastern United States. Volume 1. University of North Carolina Press, Chapel Hill, North Carolina, USA.

Mitchell, T. 1962. Bees of the eastern United States. Volume 2. University of North Carolina Press, Chapel Hill, North Carolina, USA.

Moisan-Deserres, J., M. Girard, M. Chagnon, and V. Fournier. 2014. Pollen loads and specificity of native pollinators of lowbush blueberry. Journal of Economic Entomology 107:1156-1162.

Moisan-DeSerres, J., M. Chagnon, and V. Fournier. 2015. Influence of windbreaks and forest borders on abundance and species richness of native pollinators in lowbush blueberry fields in Québec, Canada. Canadian Entomologist 147:432-442.

Morandin, L. A., and C. Kremen. 2013. Hedgerow restoration promotes pollinator populations and exports native bees to adjacent fields. Ecological Applications 23:829-839.

Oksanen, J., F. G. Blanchet, R. Kindt, P. Legendre, P. R. Minchin, R. B. O'Hara, G. L. Simpson, P. Solymos, M. H. H. Stevens, and 
H. Wagner. 2015. vegan: Community ecology package. R package version 2.3-1. https://CRAN.R-project.org/package=vegan

Ollerton, J., H. Erenler, M. Edwards, and R. Crockett. 2014. Extinctions of aculeate pollinators in Britain and the role of large-scale agricultural changes. Science 346:1360-1362.

Osborne, J. L., A. P. Martin, C. R. Shortall, A. D. Todd, D. Goulson, M. E. Knight, R. J. Hale, and R. A. Sanderson. 2008. Quantifying and comparing bumblebee nest densities in gardens and countryside habitats. Journal of Applied Ecology 45:784-792.

Packer, L., J. A. Genaro, and C. S. Sheffield. 2007. The bee genera of eastern Canada. Canadian Journal of Arthropod Identification $3: 1-32$.

Paradis, E., J. Claude, and K. Strimmer. 2004. APE: analyses of phylogenetics and evolution in $\mathrm{R}$ language. Bioinformatics 20:289-290.

Park, M. G., E. J. Blitzer, J. Gibbs, J. E. Losey, and B. N. Danforth. 2015. Negative effects of pesticides on wild bee communities can be buffered by landscape context. Proceedings of the Royal Society B 282:20150299.

Park, M. G., R. A. Raguso, J. E. Losey, and B. N. Danforth. 2016. Per-visit pollinator performance and regional importance of wild Bombus and Andrena (Melandrena) compared to the managed honey bee in New York apple orchards. Apidologie 47:145-160.

Payette, A., and D. De Oliveira. 1989. Diversité et abondance des apoides (Hymenoptera: Apoidea) dans l'agroécosystème de Saint-Hyacinthe, Québec. Le Naturaliste Canadien 116:155-165.

Peres-Neto, P. R., P. Legendre, S. Dray, and D. Borcard. 2006. Variation partitioning of species data matrices: estimation and comparison of fractions. Ecology 87:2614-2625.

Poisot, T., E. Canard, N. Mouquet, and M. E. Hochberg. 2012. A comparative study of ecological specialization estimators. Methods in Ecology and Evolution 3:537-544.

Potts, S. G., J. C. Biesmeijer, C. Kremen, P. Neumann, O. Schweiger, and W. E. Kunin. 2010. Global pollinator declines: trends, impacts and drivers. Trends in Ecology and Evolution 25:345353.

Rader, R., J. Reilly, I. Bartomeus, and R. Winfree. 2013. Native bees buffer the negative impact of climate warming on honey bee pollination of watermelon crops. Global Change Biology 19:31033110.

Rands, S. A., and H. M. Whitney. 2010. Effects of pollinator density-dependent preferences on field margin visitations in the midst of agricultural monocultures: A modelling approach. Ecological Modelling 221:1310-1316.

Rao, S., and W. Stephen. 2010. Abundance and diversity of native bumble bees associated with agricultural crops: The Willamette Valley Experience. Psyche: A Journal of Entomology 2010:1-9.

R Core Team. 2015. R version 3.2.3. R Project for Statistical Computing, Vienna, Austria. http://www.r-project.org

Ricketts, T. H., J. Regetz, I. Steffan-Dewenter, S. A. Cunningham, C. Kremen, A. Bogdanski, B. Gemmill-Herren, S. S. Greenleaf, A. M. Klein, and M. M. Mayfield. 2008. Landscape effects on crop pollination services: are there general patterns? Ecology Letters 11:499-515.

Rogers, S. R., D. R. Tarpy, and H. J. Burrack. 2014. Bee species diversity enhances productivity and stability in a perennial crop. PLoS ONE 9:e97307.

Roulston, T. H., and J. H. Cane. 2000. Pollen nutritional content and digestibility for animals. Plant Systematics and Evolution 222:187-209.

Rundlöf, M., A. S. Persson, H. G. Smith, and R. Bommarco. 2014. Late-season mass-flowering red clover increases bumble bee queen and male densities. Biological Conservation 172:138-145.

Russo, L., M. Park, J. Gibbs, and B. Danforth. 2015. The challenge of accurately documenting bee species richness in agroecosystems: bee diversity in eastern apple orchards. Ecology and Evolution 5:3531-3540.

Sardinas, H. S., and C. Kremen. 2014. Evaluating nesting microhabitat for ground-nesting bees using emergence traps. Basic and Applied Ecology 15:161-168.
Scheper, J., M. Reemer, R. van Kats, W. A. Ozinga, G. T. J. van der Linden, J. H. J. Schaminée, H. Siepel, and D. Kleijn. 2014. Museum specimens reveal loss of pollen host plants as key factor driving wild bee decline in The Netherlands. Proceedings of the National Academy of Sciences USA 111:17552-17557.

Schulp, C. J. E., S. Lautenbach, and P. H. Verburg. 2014. Quantifying and mapping ecosystem services: demand and supply of pollination in the European Union. Ecological Indicators 36:131-141.

Senapathi, D., L. G. Carvalheiro, J. C. Biesmeijer, C.-A. Dodson, R. L. Evans, M. McKerchar, R. D. Morton, E. D. Moss, S. P. Roberts, and W. E. Kunin. 2015. The impact of over 80 years of land cover changes on bee and wasp pollinator communities in England. Proceedings of the Royal Society B 282:20150294.

Shackelford, G., P. R. Steward, T. G. Benton, W. E. Kunin, S. G. Potts, J. C. Biesmeijer, and S. M. Sait. 2013. Comparison of pollinators and natural enemies: a meta-analysis of landscape and local effects on abundance and richness in crops. Biological Reviews 88:1002-1021.

Sheffield, C. S. 2014. Pollination, seed set and fruit quality in apple: studies with Osmia lignaria (Hymenoptera: Megachilidae) in the Annapolis Valley, Nova Scotia, Canada. Journal of Pollination Ecology 12:120-128.

Sheffield, C. S., P. G. Kevan, A. Pindar, and L. Packer. 2013. Bee (Hymenoptera: Apoidea) diversity within apple orchards and old fields in the Annapolis Valley, Nova Scotia, Canada. Canadian Entomologist 145:94-114.

Simidchiev, T. 1976. Study on the nectar and honey productivity of red raspberry (Rubus idaeus L.) and European blackberry (Rubus fructicosus L.). Gradinarska I Lozarska Nauka 13:42-49.

Tardif, B., G. Lavoie, and Y. Lachance. 2005. Atlas de la biodiversité du Québec: les espèces menacées ou vulnérables. Gouvernement du Québec, Ministère du Développement Durable, de l'Environnement et des Parcs, Direction du Développement Durable, du Patrimoine Écologique et des Parcs, Québec, Quebec, Canada.

Todd, K. J., M. M. Gardiner, and E. D. Lindquist. 2016. Mass flowering crops as a conservation resource for wild pollinators (Hymenoptera: Apoidea). Journal of the Kansas Entomological Society 89:158-167.

Tuell, J. K., J. S. Ascher, and R. Isaacs. 2009. Wild bees (Hymenoptera: Apoidea: Anthophila) of the Michigan highbush blueberry agroecosystem. Annals of the Entomological Society of America 102:275-287.

Venjakob, C., A. M. Klein, A. Ebeling, T. Tscharntke, and C. Scherber. 2016. Plant diversity increases spatio-temporal niche complementarity in plant-pollinator interactions. Ecology and Evolution 6:2249-2261.

Venturini, E. M., F. A. Drummond, A. K. Hoshide, A. C. Dibble, and L. B. Stack. 2016. Pollination reservoirs for wild bee habitat enhancement in cropping systems: a review. Agroecology and Sustainable Food Systems 41:101-142.

Vickruck, J. L., S. M. Rehan, C. S. Sheffield, and M. H. Richards. 2011. Nesting biology and DNA barcode analysis of Ceratina dupla and C. mikmaqi, and comparisons with C. calcarata (Hymenoptera: Apidae: Xylocopinae). Canadian Entomologist 143:254 262.

Westphal, C., I. Steffan-Dewenter, and T. Tscharntke. 2003. Mass flowering crops enhance pollinator densities at a landscape scale. Ecology Letters 6:961-965.

Westphal, C., I. Steffan-Dewenter, and T. Tscharntke. 2009. Mass flowering oilseed rape improves early colony growth but not sexual reproduction of bumblebees. Journal of Applied Ecology 46:187-193.

Whitney, G. G. 1984. The reproductive biology of raspberries and plant-pollinator community structure. American Journal of Botany $71: 887-894$

Willmer, P. G., A. A. M. Bataw, and J. P. Hughes. 1994. The superiority of bumblebees to honeybees as pollinators: insect visits to raspberry flowers. Ecological Entomology 19:271-284. 
Winfree, R., N. M. Williams, H. Gaines, J. S. Ascher, and C. Kremen. 2008. Wild bee pollinators provide the majority of crop visitation across land-use gradients in New Jersey and Pennsylvania, USA. Journal of Applied Ecology 45:793-802.

doi/10.1002/eap.1713/full

doi.org/10.5061/dryad.841vq48.
Wratten, S. D., M. Gillespie, A. Decourtye, E. Mader, and N. Desneux. 2012. Pollinator habitat enhancement: benefits to other ecosystem services. Agriculture, Ecosystems and Environment 159:112-122. 